\title{
Pedagogical development in local anaesthetic training in paediatric dentistry using virtual reality simulator
}

\author{
S. $\operatorname{Zafar}^{1}$ (D) A. Siddiqi ${ }^{2}$ (D) M. Yasir ${ }^{3}$ D J. J. $\operatorname{Zachar}^{1}$ (D)
}

Received: 25 October 2020 / Accepted: 15 January 2021 / Published online: 10 February 2021

(c) Crown 2021

\begin{abstract}
Purpose With the advancements in technology, dental pedagogy has also evolved, and new learning technologies have emerged. Virtual reality (VR) as an education tool in dentistry is underutilised. VR as an adjunct in local anaesthesia (LA) teaching in paediatric dentistry has not been investigated. The study aimed to investigate dental student's perception of dental LA VR simulation on a paediatric patient and to determine whether this can improve students learning experience.

Methods Seventy-one students participated in a self-administered questionnaire before and after the use of dental LA VR simulator. Descriptive analysis was performed to determine the perceptions of experience gained through VR. The data were tabulated, graphed, and analysed using SPSS and GraphPad Prism software.

Results The study noted that $89.9 \%$ of participants perceived that it would improve their LA skills. After using dental LA VR, $83.1 \%$ of participants experienced more engaged in the learning activity, and $55.0 \%$ of participants agreed/strongly agreed that it improved their understanding of anatomical landmarks. Around $56.4 \%$ of participants agreed/strongly agreed that it added value compared with traditional LA teaching methods.

Conclusion It can be concluded that the use of VR simulation can enhance students engagement and learning experience in paediatric dentistry settings and can be used as an additional means of LA training.
\end{abstract}

Keywords Dental education $\cdot$ Dental students $\cdot$ Local anaesthesia $\cdot$ Paediatric dentistry $\cdot$ Virtual reality

\section{Introduction}

Pain is considered as one of the critical factors in developing dental anxiety in children (Ram, Peretz 2002; Kuscu et al. 2013). Pain due to inadequate analgesia during treatment can result in patients avoiding or postponing dental treatment (Meechan et al. 2005). Dental pain can be managed pharmacologically using the topical application, local anaesthesia (LA) in combination with relative or general anaesthesia during the procedure. Local anaesthesia is considered a

S. Zafar

s.zafar@uq.edu.au

1 School of Dentistry, The University of Queensland, 288 Herston Road, Herston, QLD 4006, Australia

2 School of Dentistry and Oral Health, Griffith University, Cnr Parkland Drive and Olsen Avenue, Southport, QLD 4222, Australia

3 Department of Information Science, University of Otago, New Zealand, 362 Leith Street, Dunedin, Otago 9016, New Zealand mandatory practice in paediatric dentistry before exodontia, restorative work and pulp treatment (Mladenovic et al. 2019).

Administering LA needles in child's mouth is incredibly stressful process for both the patients as well as dental students/dentists (Dower Jr et al. 1995). Achieving successful anaesthesia is vital for paediatric patient care and comfort, so it is essential dental students can master this clinical skill (Mladenovic et al. 2019). Management of the paediatric patients pose a challenge to dental students, and is mostly attributed to the child's lack of coping skills with the dental settings, resulting in an inability to sit still for invasive or extended dental treatments (Kan et al. 2019). The unpleasant dental experience for a child can cause psychologic harm resulting in dental fear and avoidance of treatment that could persist to adulthood. Similarly, dental students often experience higher levels of stress while treating children, and providing preclinical training to dental students for paediatric procedures could make students more efficient and confident in real-life clinical situations with child patients (Zafar and Zachar 2020). 
In dentistry, both intellectual and manual dexterity skills of an operator are the key elements. Most dental curriculum includes didactic, preclinical and clinical training for dental LA delivery (Hanson 2011). However, despite theoretic and preclinical training, many students struggle while administrating LA for the first time in a paediatric clinical setting (Mladenovic et al. 2019). It is important that the transition from preclinical training to the clinic practice remain smooth for the students (Hanson 2011; Hanson et al. 2006). In this regard, simulation training is considered an essential step towards successful patient management, and students must receive sufficient preclinical training on LA administration before they treat the actual paediatric patient (Mladenovic et al. 2019).

Globally, a range of techniques has been employed to teach LA administration in the dental curriculum. Research has shown that the transition to the first injection to a patient is often tricky for dental students (Brand et al. 2010; Knipfer et al. 2018). Historically, dental students have been trained for LA administration around teeth by injecting on each other and manikin heads before starting actual clinical sessions. LA manikin heads are battery-operated manikins that provide visual and audio feedback to the students as they attempt their injections. However, there are few limitations, such as anatomical structures not being as accurate to real patients and unable to use LA solution in the phantom head. The peer-to-peer administration of LA is the most common practice in many dental schools and has been demonstrated effective LA learning model (Malamed 2004; Brand et al. 2008, 2010; Rosenberg et al. 2009; Knipfer et al. 2018). However, the ethical, legal, wellbeing and consent issues have been raised for this model. Hence, dental schools are moving away from this model (Rosenberg et al. 2009; Hossaini 2011). Two recent studies have used video clips as an alternative way to teach LA skills, and both studies found the method was effective in improving students' confidence and psychomotor skills for the procedure (Kenny et al. 2018; Wong et al. 2019).

In this regard, some new techniques including VR have been suggested that provide hands-on experience without practicing on real patients (Hanson 2011). Virtual realitybased training tools have been recently introduced into the dental education (Hanson 2011). Such educational tools provide $3 \mathrm{D}$ (three dimensional) learning settings that are close to a real sense of interaction, so enhance clinical learning of dental students (Correa et al. 2017). Further, a VR setting enables the students to differentiate intraoral anatomical structures that are considered critical elements in obtaining clinical skills to deliver LA due to the three-dimensional nature of the setup (Hanson 2011; Hanson et al. 2006). Other benefits provided by VR include trial and error as students can practice several times before dealing with real patients, automatic evaluations of performance and repeated training in a controlled environment (Correa et al. 2017). In VR simulation, the student can pause and review his/ her account at any stage and seek guidance. VR simulation as an educational tool has been successfully used in other disciplines of dentistry such as restorative (Zafar et al. 2020) and head and neck anatomy (Zafar and Zachar 2020) and have significantly improved students' knowledge and clinical skills (Mladenovic et al. 2019; Llena et al. 2018). Furthermore, recent research has demonstrated positive feedback from students regarding learning through VR within dentistry (Vuchkova et al. 2011). However, whether such learning techniques can be useful in gaining knowledge in dental LA deliver is yet to investigate. Hence, the main focus of the study was to address this gap in dental pedagogy. The present study aimed to determine the effectiveness of a novel VR LA simulation tool in improving dental student's skills and knowledge as opposed to student's experience on conventional phantom heads using a paediatric model. To the knowledge of authors, this is the first study who has investigated the VR simulation tool to train LA administration using a paediatric model.

\section{Methods}

This study presents the development of a LA VR training simulator for procedures, including the inferior alveolar nerve block, supraperiosteal buccal infiltration and palatal infiltration. The Oculus Quest is all-in-one VR headset (Facebook Technologies LLC, California, USA) that is fully standalone and features six degrees of freedom. Oculus insight tracking has built-in sensors that translate operator's movements into VR and provide room scale tracking. The oculus touch controllers allow the operators hands and gestures to appear in VR with intuitive and realistic precision. It is portable, requires minimal setup and the images can be broadcasted on computer screen as shown in Figs. 1 and 2. It combines aspects of VR by superimposing digital 3D holograms and 360-degree spatial sound onto the real world (Nayyar, Nguyen 2018). The result is an experience that seamlessly merges digital content into reality and allows viewers to learn and discover content by walking around virtual objects and interacting with them (Jantjies et al. 2018). Wearing an oculus headset, the wearer is transported to a virtual dental clinic, where a patient awaits a dental procedure.

\section{Software development}

The LA VR simulator software was developed by authors using Zbrush (Pixologic Inc, Santa Monica, CA, USA), Blender (Blender Foundation, Amsterdam NL), Unity3D (Unity Technologies, Copenhagen, DK) and OpenGL 


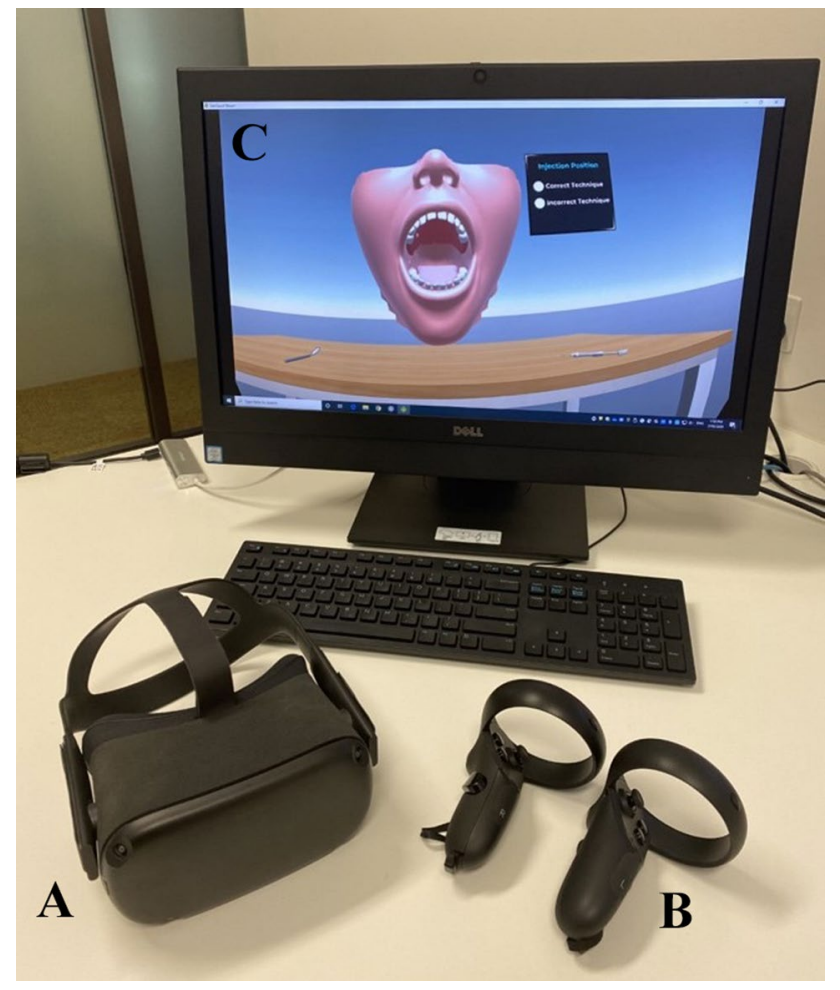

Fig. 1 Paediatric virtual reality local anaesthetic setup. a Oculus Quest headset b Hand controllers. c Stream function with SideQuest

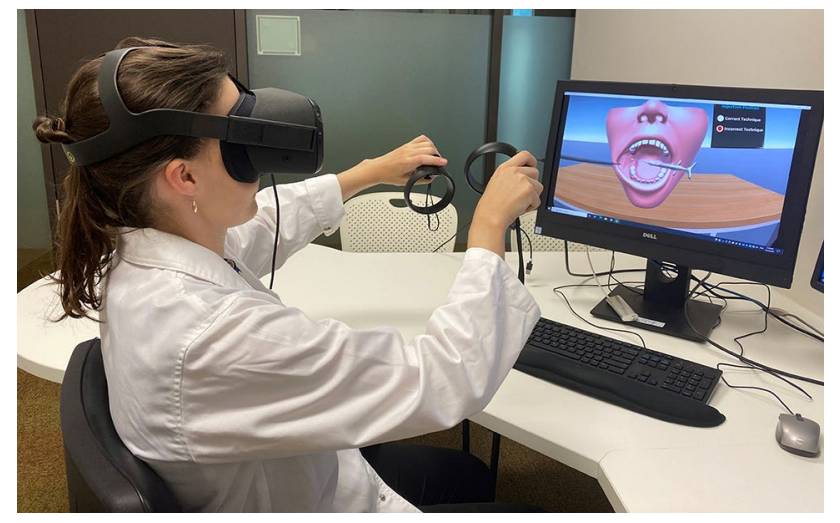

Fig. 2 Student practicing paediatric virtual reality local anaesthetic setup with the Oculus Quest

(Khronos Group, Oregeon, USA). All 3D objects (including teeth, mouth, mirror and syringe) in the software were developed in Zbrush and Blender whereas programming of simulator software was programmed on Unity3D and OpenGL. Agile software development technique (Beck et al. 2001) was used to build the simulation software. Agile software development is the idea of iterative development where requirements and solutions evolve through collaboration between self-organising and cross-functional teams. The software was installed in oculus quest and was live streamed using SideQuest (SideQuest Studios, Mainz, Germany) in Windows computer (OptiPlex 7450 All-in-One Desktop, Dell Inc, Austin, USA).

\section{Ethics approval and participant recruitment}

Ethics approval was obtained from the Human Research Ethics Committee at The University of Queensland (UQ), Approval no. 2019002946. The study involved the completion of a pre-training survey and post-training survey by second-year dental students enrolled in a Bachelor of Dental Science (Honours) at UQ. The survery was modified from a previous virtual relaty questionairee study (Zafar and Zachar 2020). All second-year dental students enrolled in DENT2050 (Dental Practice II) were invited to participate in the study. The participant consent and information sheet, along with the surveys, were distributed to students who agreed to participate in the study.

Within the UQ dental curriculum, dental students in second year receive a total of 18 -h of dental LA training. This includes 6-h of didactic lectures, a 3-h tutorial, 3-h of preclinical training and 6-h of clinical training (Fig. 3). During the preclinical training session, students completed LA training on traditional phantom heads (Local Anaesthesia Manikin Model, OneDental, Miami, QLD, Australia) for $30 \mathrm{~min}$ and completed the pre-training survey prior to the dental LA VR training.

This was followed by 30-min of dental LA VR training with the Oculus Quest (Oculus VR, Irvine, CA, USA). After completion of the VR training, the students completed a post-training survey. The dental LA VR software program enabled students to perform an inferior alveolar nerve block, supraperiosteal buccal infiltration and a palatal infiltration on a paediatric patient (Fig. 4). The virtual paediatric patient was 6 years of age with a primary dentition. The students were able to hold a mirror for soft tissue retraction and a dental syringe for injections. This was performed by holding onto the grip buttons on the oculus touch controllers. They were also able to simulate the injection of LA with the trigger button. The trigger button would activate haptic feedback during the injection. The software also informed students whether the techniques were correct or incorrect and injection target sites were also visible for practice. Students first received the demonstration for using both techniques and then they worked in pairs and this was streamed via a computer so that students could watch each other perform the LA procedure (Figs. 1 and 2). To ensure confidentiality, surveys were separated from the consent forms and collected anonymously into a designated survey box. The survey contained open ended and Likert scale questions which comprise of five response options (strongly agree, agree, neutral, disagree and strongly disagree), including demographics and students experience of the VR LA training. 


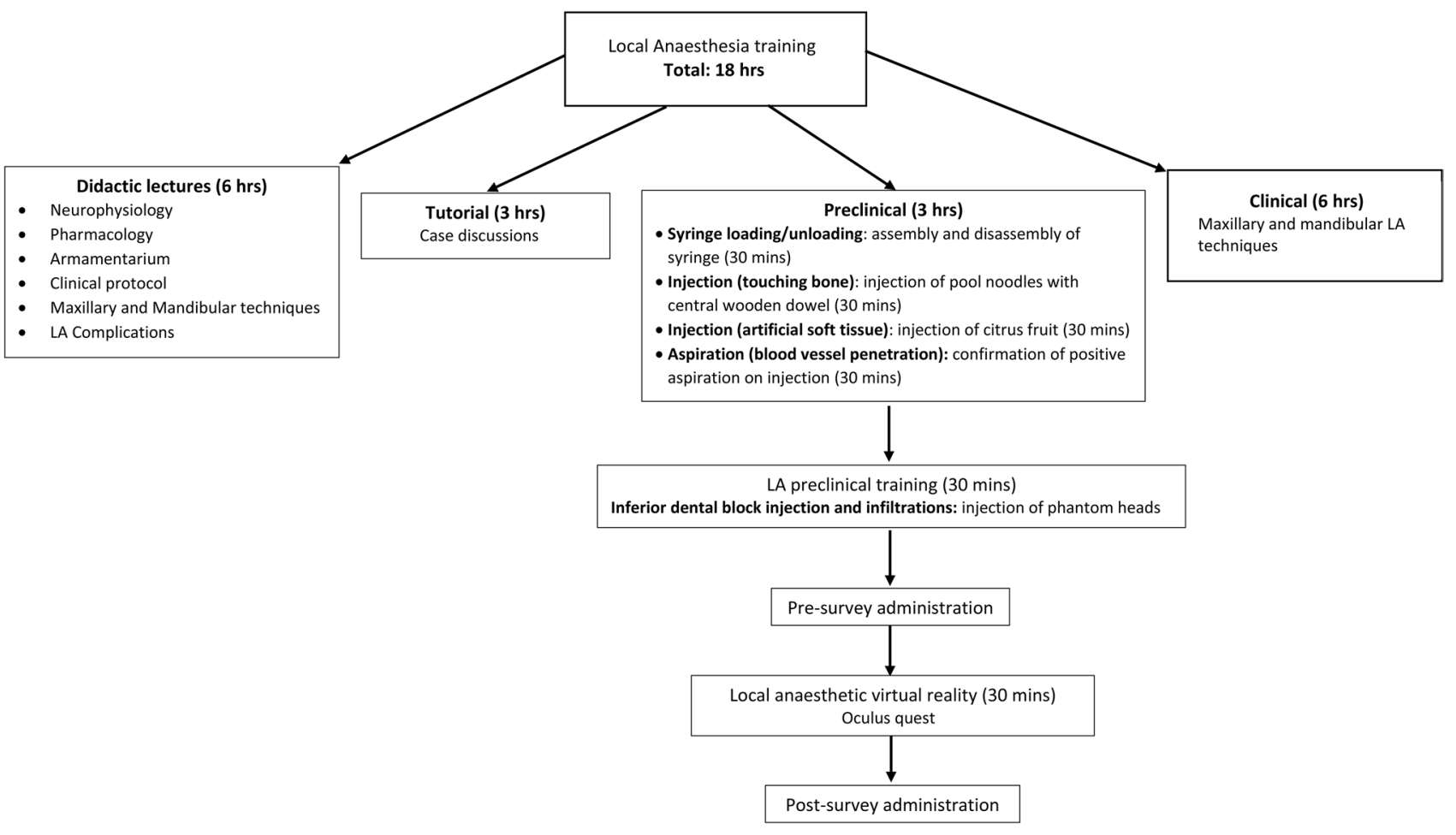

Fig. 3 Local anaesthesia training protocol at UQ dental curriculum
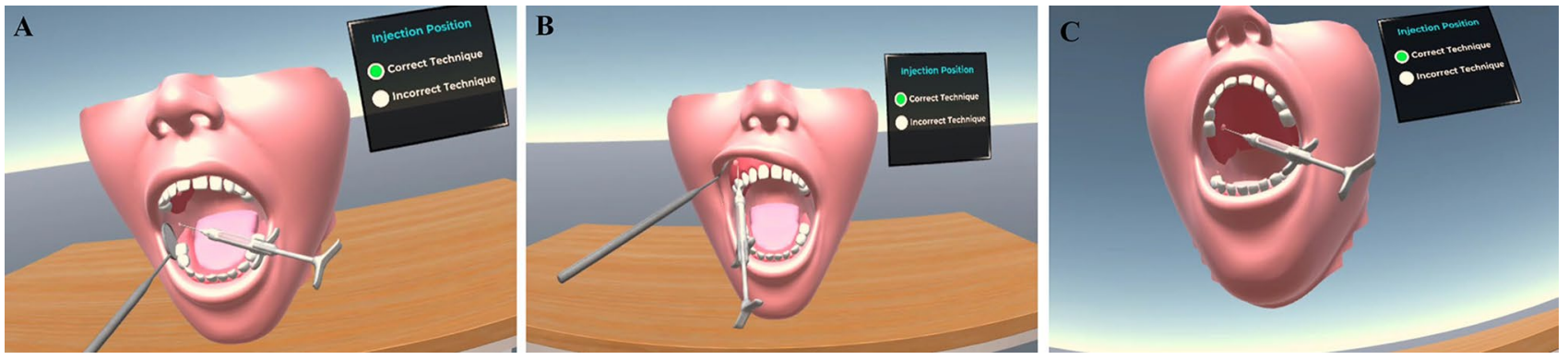

Fig. 4 Demonstration of paediatric virtual reality local anaesthetic administration techniques. a Inferior alveolar nerve block. b Buccal supraperiosteal infiltration. $\mathbf{c}$ Palatal supraperiosteal infiltration

\section{Statistical analysis}

The data were tabulated on Microsoft Excel spreadsheet and then imported into IBM SPSS Statistics for Macintosh v26 (IBM, Armonk, NY, USA) for descriptive analysis and GraphPad PRISM 8.0 software (GraphPad Software, San Diego, Calif., USA) for collation and creation of appropriate graphs. Responses were summarised, and comparisons were made. The output of data was presented in a table format (total responses and percentage) as well as a graphical format. Specific data analysis tests performed included descriptive statistics, such as frequencies and percentages.

\section{Results}

A total of 75 students were invited to participate in the study, and 69 students agreed to participate in the pre-training survey and 71 students agreed to participate in the posttraining survey. Of the total number of participants $(n=71)$, 37 subjects were female and 34 were male. The age of the participants ranged from 18 to 32 years with a mean age of 20.87 years. With regard to regular use of devices, $95.7 \%$ of participants used a smart phone regularly and $94.2 \%$ used a laptop regularly. On the other hand, $13.0 \%$ of participants used a smart watch and $42 \%$ used a tablet/iPad regularly. In 
addition to this, $10.1 \%$ of the students had previous experience with VR headsets. The students' expectations prior to the use of the dental VR LA were assessed through a series of statements that students indicated their agreement to (Table 1).

The results of the pre-training survey showed that majority of the dental students agreed (43.5\%) or strongly agreed (39.1\%) that they were excited about using the dental LA VR device. Also $85.5 \%$ agreed/strongly agreed that they expected the VR device to be user-friendly. Over half of participants perceived that it would assist in their learning with $62.3 \%$ of participants who agreed and $31.9 \%$ of participants who strongly agreed. Similarly, over half of participants agreed $(53.6 \%)$ or strongly agreed (13.0\%) that VR would appear realistic. It was also found that $62.3 \%$ of participants who agreed and $23.1 \%$ of participants who strongly agreed that it would add value compared with traditional learning methods. Also $69.9 \%$ agreed and $20.3 \%$ strongly agreed that it would improve their local anaesthesia administration skills and similarly, $66.7 \%$ agreed and $27.5 \%$ strongly agreed that seeing the $3 \mathrm{D}$ anatomical structures through VR will increase their understanding of local anaesthetic administration.

The students' perceptions after the use of the dental LA VR software were assessed through a series of statements that students indicated their agreement to (Table 2). The results of the post-training survey showed that $80.3 \%$ of participants agreed/strongly agreed that they felt comfortable using the virtual reality device, $53.6 \%$ agreed/strongly agreed it was user-friendly and $52.1 \%$ of participants agreed/ strongly agreed that the LA VR looked realistic. It was also found that $55 \%$ of participants agreed that the $3 \mathrm{D}$ anatomical structures improved their understanding of LA administration and $36.7 \%$ felt that it improved their skills (Fig. 5). The

Table 1 Pre-training LA VR perception of dental students

\begin{tabular}{|c|c|c|c|c|c|}
\hline \multirow[t]{2}{*}{ Statement } & \multicolumn{5}{|l|}{ Responses (\%) } \\
\hline & Strongly agree & Agree & Neutral & Disagree & $\begin{array}{l}\text { Strongly } \\
\text { disagree }\end{array}$ \\
\hline I am excited about using the paediatric dental local anaesthetic VR & 39.1 & 43.5 & 14.5 & 0.0 & 2.9 \\
\hline I expect the paediatric dental LA VR to be user-friendly & 20.3 & 65.2 & 11.6 & 1.4 & 1.4 \\
\hline I expect working on paediatric LA VR is realistic & 13.0 & 53.6 & 30.4 & 1.4 & 1.4 \\
\hline I expect that paediatric dental LA VR will assist my learning & 31.9 & 62.3 & 4.3 & 0.0 & 1.4 \\
\hline $\begin{array}{l}\text { I expect that using paediatric dental LA VR will improve my local anaesthesia adminis- } \\
\text { tration skills }\end{array}$ & 20.3 & 69.6 & 8.7 & 0.0 & 1.4 \\
\hline $\begin{array}{l}\text { I expect working on the paediatric dental LA VR will allow me to see the 3D anatomical } \\
\text { structures that will increase my understanding for LA administration }\end{array}$ & 27.5 & 66.7 & 4.3 & 0.0 & 1.4 \\
\hline $\begin{array}{l}\text { I expect added value in the use of paediatric dental LA VR in my training compared to } \\
\text { relying solely on traditional methods of training of LA training }\end{array}$ & 23.2 & 62.3 & 13.0 & 0.0 & 1.4 \\
\hline
\end{tabular}

Table 2 Post-training LA VR perception of dental students

\begin{tabular}{|c|c|c|c|c|c|}
\hline \multirow[t]{2}{*}{ Statement } & \multicolumn{5}{|l|}{ Responses (\%) } \\
\hline & Strongly agree & Agree & Neutral & Disagree & $\begin{array}{l}\text { Strongly } \\
\text { disagree }\end{array}$ \\
\hline I felt comfortable using the paediatric dental local anaesthetic VR & 29.6 & 50.7 & 14.1 & 4.2 & 1.4 \\
\hline Paediatric dental LA VR is user-friendly & 11.3 & 42.3 & 33.8 & 11.3 & 1.4 \\
\hline 3D images of the anatomy in the paediatric dental LA VR looked realistic & 11.3 & 40.8 & 35.2 & 12.7 & 0.0 \\
\hline Using paediatric dental LA VR assisted my learning & 8.5 & 47.9 & 26.8 & 16.9 & 0.0 \\
\hline $\begin{array}{l}\text { 3D anatomical structures on paediatric dental LA VR improved my understanding of } \\
\text { anatomical landmarks in a paediatric patient }\end{array}$ & 8.5 & 46.5 & 25.4 & 16.9 & 2.8 \\
\hline $\begin{array}{l}\text { The use of paediatric dental LA VR added value in my training compared to relying } \\
\text { solely on traditional methods of training }\end{array}$ & 9.9 & 46.5 & 32.4 & 8.5 & 2.8 \\
\hline $\begin{array}{l}\text { The use of paediatric dental LA VR improved my skills of local anaesthesia administra- } \\
\text { tion in a paediatric patient }\end{array}$ & 8.5 & 28.2 & 38.0 & 22.5 & 2.8 \\
\hline When using the paediatric dental LA VR, I felt I was engaged in a learning activity & 23.9 & 59.2 & 12.7 & 2.8 & 1.4 \\
\hline $\begin{array}{l}\text { I think the use of dental LA VR would be helpful in teaching local anaesthesia adminis- } \\
\text { tration technique on a paediatric patient }\end{array}$ & 14.1 & 46.5 & 22.5 & 12.7 & 4.2 \\
\hline
\end{tabular}




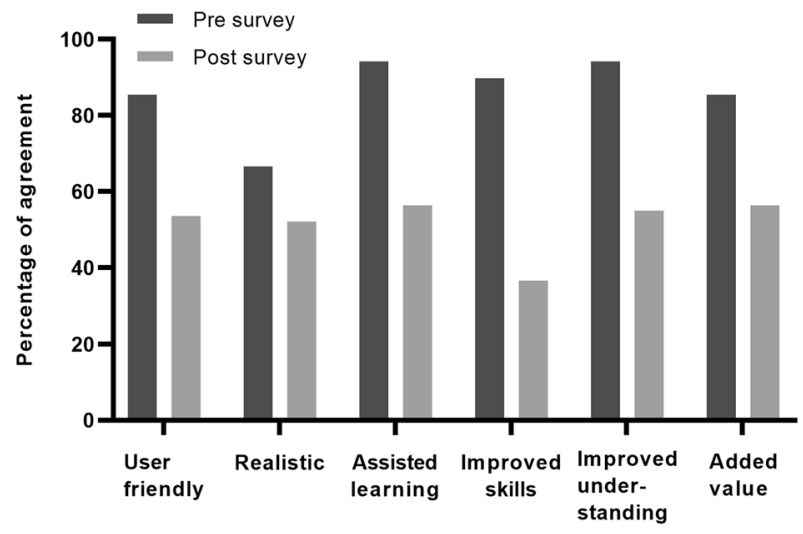

Fig. 5 Comparison of pre- and post-training survey responses

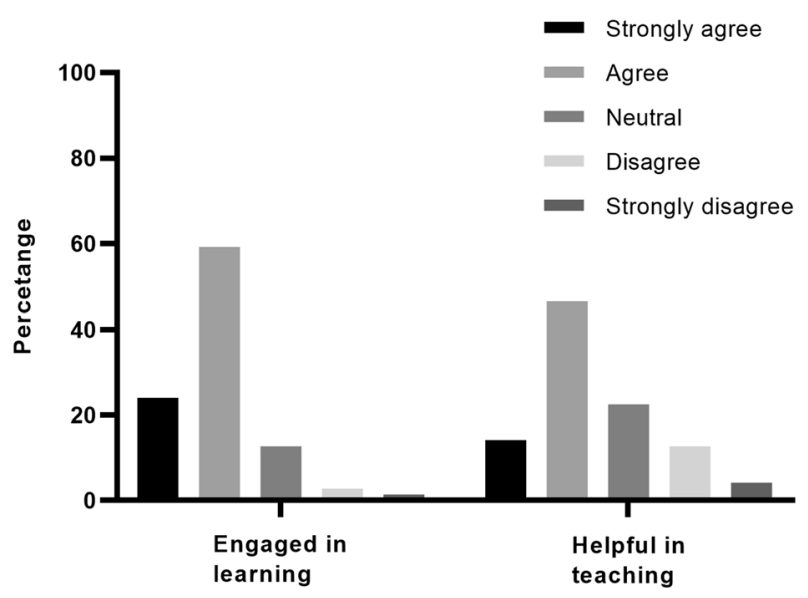

Fig. 6 Responses from the statements: 'When using the paediatric dental local anaesthetic VR, I felt I was engaged in a learning activity and I think the use of dental local anaesthetic VR would be helpful in teaching local anaesthesia administration technique on a paediatric patient'

results also demonstrated that $56.4 \%$ agreed/strongly agreed that it added value in training compared with relying solely on traditional methods and $56.4 \%$ agreed/strongly agreed that it assisted in their learning (Fig. 5). 83.1\% of participants agreed/strongly agreed that they felt engaged in the learning activity and $60.6 \%$ found it was helpful in teaching LA (Fig. 6). It was also found that $63.4 \%$ of participants agreed or strongly agreed that it should be an optional part in the dental curriculum. Overall, $71.8 \%$ of participants disagreed that LA VR teaching should replace traditional phantom head training. Student comments with regard to learning included, "Fun experience overall", "Felt like I was having fun instead of learning", "It was a fun interactive method of identifying landmarks and activity boosts confidence". Comments with regard to technical difficulties included "Found it difficult to retract the soft tissues", "Not $100 \%$ friendly for those with prescription glasses that don't fit in the headset".
Suggested improvements mentioned by students included, "Would prefer more tactile feeling" and "Would like more haptic feedback such as touching bone and injecting through tissue".

\section{Discussion}

The results of the study suggest that the use of VR offers an additional mean of LA training in paediatric dentistry; however, it cannot be used as a replacement for traditional modes of phantom head training. Furthermore, the study also noted that dental graduates do not feel sufficiently prepared in delivering LA in paediatric patients.

The University of Sydney, Australia, has shifted from peer-to-peer administration of LA to simulation model using manikins. The team of researchers have investigated students' perceived level of confidence and anxiety before and after their first LA to a child and an adult after using LA simulation model. No significant differences were noted when confidence and stress of the two cohorts were analysed. The study also concluded that the LA manikin simulation offers a safe learning environment without ethical and legal concerns (Wong et al. 2020). Another study showed that the use of dental anaesthesia simulation model had a positive impact on motor skills and confidence of students (Reyes-Acuca et al. 2020). These results are in line with the current study findings.

Clinicians attempt to master the skills of administrating relatively painless injection as it is a key to having a cooperative paediatric patient (Ram and Peretz 2002; Kuscu et al. 2013). There is a constant search for newer models to enhance student training and experience of LA, especially in paediatric patients. A recent study by Mladenovic et al. (2020) evaluated the effects of AR (Augmented Reality) simulation application (commercially available) on students' learning and acute stress level while administering LA to paediatric patients compared with standard teaching methods. The authors concluded that the use of AR might improve student's control of the syringe during their first LA injection to paediatric patients but did not reduce their anxiety levels. A mixed-reality adult model was developed by Utah State University, the USA for dental hygiene education, and the utilisation of the model demonstrated increased confidence of the participants (Hanson 2011). A recent survey indicated that $92 \%$ of the students supported the use of a 3D learning simulation system for LA techniques (Pacheco 2017). This suggests that a combination of augmenta reality and virtual reality in beneficial in student learning.

Simulations are an effective way of providing opportunities for students to interact with situations that mimic real world (Nayyar and Nguyen 2018). Although the new generations are raised in a digital era where the technological 
advancements are introduced early in their life, and almost $90 \%$ of the participants were using digital technology regularly, but only $10.1 \%$ of the students previously received any VR-based simulation training. The administration of LA is often considered as a complex learning task, requiring multiple competencies within several domains, such as anatomical knowledge and technical skills. The results of the present study showed that more than half of the participants agreed/strongly agreed that the use of VR LA assisted and added value to their learning. Only $37 \%$ of students felt that it improved their LA administration skills. The reason for this is because some students were unable to adapt to the technology in a short time period (30 min time interval was provided for each student). A longer time period would be suggested in future student teaching sessions.

Previous studies have shown that training utilising simulation-based LA teaching could enhance learning outcomes, improve motor skills and the confidence of dental students (Marei, Al-Jandan 2013; Reyes-Acuca et al. 2020). In this study, the pre-training survey focussed on students' perception and expectations of LA VR before they began hands-on LA training. The study noted that $83 \%$ of the students enjoyed their learning while using technology. They expected that the technology would be user-friendly (86\%), realistic $(67 \%)$, allow them to visualise the anatomy $(94 \%)$. The results of the post-training survey indicated that $80 \%$ of the students felt comfortable using the technology, 54\% found it user-friendly, and 52\% thought that the anatomy looked realistic. These results showed that the use of the LA system met the expectations of over $50 \%$ of the participants. Almost $60 \%$ of the students agreed with the statement that the use of dental LA VR would help teach LA administration technique on a paediatric patient.

Working in LA VR simulation environment created an imaginary visual environment and provided with a haptic realism in which students can feel when injecting into the correct anatomical landmarks. This also allowed students to practice in a space that is safe for both them, tutors and the patients. Moreover, the LA VR simulation systems permitted students to make mistakes as part of the learning process, but without any harm to patients. The ability to explore these actions and their consequences provide rich learning experiences and are further enhanced by automated feedback provided by the LA VR system of their techniques.

Around $83 \%$ of the student's in the present study strongly agreed or agreed regarding their engagement in the learning activity. These outcomes concur with other reports, which have demonstrated that the use of simulation in the classroom can significantly improve students learning, engagement, and motivation (Zafar and Zachar 2020; Zafar et al. 2020).

A limitation to this study is that there could be digital divide among those who have do not feel comfortable using electronic devices and may not adapt to newer technology. Also, the students using prescription glasses found it difficult to adjust the headset over their glasses. Furthermore, room scale tracking and guardian boundaries is different for various heights and the software needs to add height adjustments so that tall students could complete the task without crouching.

The LA VR simulator provides a safe alternative approach where students can get hand-on-experience on LA during the COVID-19 pandemic as it does not require patient contact and can be used both on campus and off campus. There has been a shift towards embedding the digital dentistry into the curriculum, and the current technology could enhance students' learning experience. Dental schools and universities should be more prepared in investing their time and efforts in the development of similar dental technologies to ensure safety and training of dental students post-COVID-19 pandemic. The other advantages of the VR simulation include the reduction in the overall running cost of dental materials; it is without any occupational hazards and risks and is user-friendly (Zafar et al. 2020). It possesses the potential to incorporate various clinical scenarios. Although the study showed a promising positive impact on student's learning, further research using the enhanced dental environment and the haptic feedback with a greater magnitude is recommended.

\section{Conclusions}

The outcomes of the study suggest that the use of VR can provide an additional mean of LA training in paediatric dentistry; however, it cannot substitute the contemporary model of practice. VR can be used as an adjunct educational tool in the learning of LA as it improves student engagement. With the advancing dental pedagogy, new technologies like VR simulation can be used as an additional tool to support students learning.

Acknowledgements The authors would like to acknowledge Justin Flohr (Principal Information Technology Support Officer) and Jessica Tsai (Senior Learning Designer in Virtual Learning Environments) for their assistance in providing technical support for the Oculus Quest headsets, thus making the data collection of this study possible. We also would like to thank Dr Matthew Nangle (Senior Lecturer) for his assistance in the implementation of this novel local anaesthetic virtual learning experience within the dental curriculum. Lastly, we would like to thank all students who participated in the study for their time and enthusiasm.

Author contributions SZ, AS, MY, and JZ conceived the ideas; SZ and JZ collected the data; JZ analysed the data; SZ, AS and JZ led the writing. MY led software development. 


\section{Compliance with ethical standards}

Conflict of interest The authors have no conflict of interest to declare.

\section{References}

Beck K, Beedle M, Van Bennekum A, Cockburn A, Cunningham W, Fowler M, et al. Principles behind the agile manifesto. Agile Alliance. 2001;2001:1-2.

Brand H, Kuin D, Baart J. A survey of local anaesthesia education in European dental schools. Eur J Dent Educ. 2008;12(2):85-8.

Brand HS, Baart JA, Maas NE, Bachet I. Effect of a training model in local anesthesia teaching. J Dent Educ. 2010;74(8):876-9.

Correa CG, Machado MADAM, Ranzini E, Tori R, Nunes FDLS. Virtual Reality simulator for dental anesthesia training in the inferior alveolar nerve block. J Appl Oral Sci. 2017;25(4):357-66.

Dower J Jr, Simon J, Peltier B, Chambers D. Patients who make a dentist most anxious about giving injections. CDA J. 1995;23(9):35.

Hanson K, Jones N, Krantz M, Law H. Techniques for administering local anesthesia utilizing mixed-reality technology. J Dent Res. 2006;85(Special Issue A).

Hanson KM. The utilization of mixed-reality technologies to teach techniques for administering local anesthesia 2011.

Hossaini M. Teaching local anesthesia in dental schools: opinions about the student-to-student administration model. J Dent Educ. 2011;75(9):1263-9.

Jantjies M, Moodley T, Maart R, editors. Experiential learning through virtual and augmented reality in higher education. International Conference on Education Technology Management. 2018.

Kan S, Ho V, Siddiqi A, Zafar S. The prevalence of percutaneous exposure incidents among staff and students treating pediatric patients. J Dent Child. 2019;86(2):81-7.

Kenny K, Alkazme A, Day P. The effect of viewing video clips of paediatric local anaesthetic administration on the confidence of undergraduate dental students. Eur J Dent Educ. 2018;22(1):57-62.

Knipfer C, Rohde M, Oetter N, Muench T, Kesting MR, Stelzle F. Local anaesthesia training for undergraduate students-how big is the step from model to man? BMC Med Educ. 2018;18(1):1-8.

Kuscu OO, Kucuktepe C, Caglar E, Cildir SK, Hacinlioglu N, Sandallı N. Role of 'Student-to-Student Local Analgesia Administration' on undergraduate students' opinions regarding 'PainFree Local Analgesia Technique' in children. Eur J Dent Educ. 2013;17(3):185-9. https://doi.org/10.1111/eje.12040.

Llena C, Folguera S, Forner L, Rodríguez-Lozano F. Implementation of augmented reality in operative dentistry learning. Eur J Dent Educ. 2018;22(1):122-30.

Malamed SF (2004) Handbook of Local Anesthesia. Elsevier Health Sciences
Marei H, Al-Jandan B. Simulation-based local anaesthesia teaching enhances learning outcomes. Eur J Dent Educ. 2013;17(1):44-8.

Meechan JG, Howlett PC, Smith BD. Factors influencing the discomfort of intraoral needle penetration. Anesth Prog. 2005;52(3):914. https://doi.org/10.2344/0003-3006(2005)52[91:FITDO I] 2.0.CO;2.

Mladenovic R, Dakovic D, Pereira L, Matvijenko V, Mladenovic K. Effect of augmented reality simulation on administration of local anaesthesia in paediatric patients. Eur J Dent Educ. 2020;24:507-12.

Mladenovic R, Pereira L, Mladenovic K, Videnovic N, Bukumiric Z, Mladenovic J. Effectiveness of augmented reality mobile simulator in teaching local anesthesia of inferior alveolar nerve block. J Dent Educ. 2019;83(4):423-8.

Nayyar A, Nguyen GN. Augmenting Dental Care: A Current Perspective. Emerging Technologies for Health and Medicine: Virtual Reality, Augmented Reality, Artificial Intelligence, Internet of Things, Robotics, Industry 4.0. Wiley-Scrivener; 2018.

Pacheco PIP (2017) The need for, and the use of, three dimensional simulation in dental education: University of Dundee.

Ram D, Peretz B. Administering local anaesthesia to paediatric dental patients-current status and prospects for the future. Int J Paediatr Dent. 2002;12(2):80-9.

Reyes-Acuca MJ, Sánchez-Lezama ZS, Capistrán-Sarmiento B, Teodoro-Isneros A, Suárez-Franco JL, Cerda-Cristerna BI. Learning of the mental nerve block technique with dental anaesthesia simulation models builds motor skills and confidence in dental students. Eur J Dent Educ. 2020;24:491-8.

Rosenberg M, Orr DL, Starley ED, Jensen DR. Student-to-student local anesthesia injections in dental education: moral, ethical, and legal issues. J Dent Educ. 2009;73(1):127-32.

Vuchkova J, Maybury TS, Farah CS. Testing the educational potential of $3 \mathrm{D}$ visualization software in oral radiographic interpretation. J Dent Educ. 2011;75(11):1417-25.

Wong G, Apthorpe HC, Ruiz K, Nanayakkara S. An innovative educational approach in using instructional videos to teach dental local anaesthetic skills. Eur J Dent Educ. 2019;23(1):28-34.

Wong G, Apthorpe HC, Ruiz K, Nanayakkara S. A tale of two teaching methods: students' clinical perspectives on administering dental local anesthetics. J Dent Educ. 2020;84(2):166-75.

Zafar S, Lai Y, Sexton C, Siddiqi A. Virtual Reality as a novel educational tool in pre-clinical paediatric dentistry training: Students' perceptions. Int J Paediatr Dent. 2020;00:1-7.

Zafar S, Zachar J. Evaluation of augmented reality application for learning dental anatomy as a novel educational tool. Eur J Dent Educ. 2020;24(2):259-65.

Publisher's Note Springer Nature remains neutral with regard to jurisdictional claims in published maps and institutional affiliations. 